\title{
Preprint \\ The Psychology of Morbid Curiosity: Development and Initial Validation of the Morbid Curiosity Scale
}

\author{
Coltan Scrivner
}

\section{Author Note}

Coltan Scrivner, Department of Comparative Human Development and Institute for Mind and Biology, The University of Chicago; Chicago, Illinois

All data and analysis code used for this manuscript can be found on the Open Science Framework repository: https://osf.io/gv52a/

Address correspondence to Coltan Scrivner, Biopsychological Science Building, 940 E. 57th Street, Chicago, IL 60637. Email: cscrivner@uchicago.edu 


\title{
PSYCHOLOGY OF MORBID CURIOSITY
}

\author{
Abstract \\ The success of horror films, popularity of true crime, and prevalence of violence in the news \\ implies that morbid curiosity is a common psychological trait. However, research on morbid \\ curiosity is largely absent from the psychological literature. In this paper, I present a novel \\ psychometric tool for assessing morbid curiosity, defined as a motivation to seek out information \\ about dangerous phenomena, and use it to investigate the psychological nature of morbid \\ curiosity. In studies 1 and $2\left(n_{\text {total }}=1370\right)$, the Morbid Curiosity Scale was developed and its \\ relationship to personality was assessed. Morbidly curious individuals were rebellious, socially \\ curious, and low in animal reminder disgust. Study $3(\mathrm{n}=317)$ demonstrated that trait morbid \\ curiosity is stable over 4-6 weeks and that morbidly curious individuals prefer movies where \\ threat is a central theme. In Study $4(\mathrm{n}=137)$, participants were presented with a choice between \\ a morbid stimulus and a highly controlled non-morbid stimulus. Morbid curiosity predicted over \\ half the variance $\left(r^{2}=.53\right)$ in decisions to further investigate a morbid stimulus. These four \\ studies provide evidence that morbid curiosity is a normally occurring psychological trait that \\ can be accurately assessed using the new 24-item Morbid Curiosity Scale.
}

Keywords: curiosity, violence, horror, disgust, morbid curiosity, threat Word count: 9540 


\section{PSYCHOLOGY OF MORBID CURIOSITY}

\section{Introduction}

Several lines of research suggest that humans are predisposed to attend to particular features of the world, such as faces, people, and potentially dangerous phenomena (Birmingham, Bischof, \& Kingstone, 2008; End \& Gamer, 2017; Koster, Crombez, Van Damme, Verschuere, \& De Houwer, 2004; Pascalis \& Kelly, 2009; Scrivner et al., 2019). Attention to some phenomenon can be understood as a mechanism by which one learns about that phenomenon. This is true regardless of the pleasantness of the phenomena. Indeed, pleasantness appears to be unrelated to interestingness (Turner \& Silvia, 2006). Moreover, the modern commercial success of violent action films and horror movies and literature, along with the prevalence of death and violence in the news, suggests that people are curious about topics which might typically be described as unpleasant.

The attentional capture and holding of unpleasant aspects of the environment may be a necessary part of learning about those aspects if their negative features would otherwise promote avoidance and prevent us from gathering important information about them. One example of this is the initial attentional capture of disgusting features. Though they inspire avoidance, disgusting features have been shown to actually capture attention and cognitive processing in the early stages of visual processing before promoting avoidance (Armstrong, Engel, Press, Sonstroem, \& Reed, 2019; Bradley, Costa, \& Lang, 2015; Wheaton et al., 2013; Xu et al., 2015). While the function of the emotion of disgust is presumably to inspire avoidance of potentially pathogenic material, one must first notice and identify the material before it can be avoided. By initially attracting attention, disgusting material can be quickly identified, and exposure can be 


\section{PSYCHOLOGY OF MORBID CURIOSITY}

minimized. Without this predisposition to initially attend to disgusting material, the possibility of longer exposure to potentially pathogenic material would be greater.

Disgusting features are not the only unpleasant things about which humans appear to have curiosity. Violence, danger, and death are historically old and cross-culturally prevalent themes in art, news, and story-telling (Davis \& McLeod, 2003; Scalise-Sugiyama, 2006; Schechter, 2005). Many rumors also feature information about threatening or potentially threatening phenomena. As the adage suggests, bad news may indeed travel more quickly than good news (Heath, Bell \& Sternberg, 2001). While a general negativity bias plays a role in the spread of information, threat in particular is often responsible for greater propagation of information (Bebbington, MacLeod, Ellison, \& Fay, 2017; Blaine \& Boyer, 2018). People also more readily believe threat-related information and perceive sources of threat-related information as more competent (Boyer \& Parren, 2015; Fessler, Pisor, \& Navarrete, 2014; Hilbig, 2009). This suggests that paying close attention to threatening information can be beneficial both in terms of personal safety as well as social esteem and credibility. Therefore, in addition to the avoidance that is inspired by disgusting and dangerous phenomena, there is pressure for information gathering - a process motivated by curiosity - when presented with disgusting and dangerous phenomena.

\section{Morbid Curiosity}

Though there appears to be no formal scientific definition, morbid curiosity is typically described as an interest in or curiosity about unpleasant things, especially death. While psychologists have extensively explored how the mind deals with death (e.g., Solomon, Greenberg, \& Pyszczynski, 2015) and curiosity has been investigated in a variety of research 


\section{PSYCHOLOGY OF MORBID CURIOSITY}

programs (Kidd \& Hayden, 2015; Loewenstein, 1994), psychologists have largely ignored morbid curiosity as a topic of study. In what appears to be the first psychological paper on morbid curiosity, Zuckerman \& Litle (1986) developed the Curiosity About Morbid Events (CAME) scale, which is composed of items that reflect an interest or enjoyment in watching violence and death. Zuckerman \& Litle (1986) reasoned that the driving factor behind curiosity about morbid events was not something inherent to the morbid events, but rather an individual's need for novel stimulation and arousal. They found that males scored higher on the CAME scale, and scores on the CAME scale correlated with sensation seeking, supporting their notion that sensation seeking correlates with morbid curiosity.

Despite being published over 30 years ago, the CAME scale has not experienced widespread use in psychology. This is surprising given that individual differences in morbid curiosity likely exist. Moreover, research on morbid curiosity and related topics has become increasingly more common (e.g., Andersen et al., 2020; Clasen, 2012; Clasen, 2017; Clasen et al., 2019; Clasen et al., 2020; Harrison \& Frederick, 2020; Kerr, 2015; Kerr et al., 2019; Martin, 2019; Niehoff \& Oosterwijk, 2020; Oosterwijk, 2017; Oosterwijk et al., 2020; Robinson et al., 2014; Scrivner 202; Scrivner \& Christensen, 2021; Scrivner et al., 2020; Scrivner et al., 2021; Stone \& Sharpley, 2008; Vicary \& Fraley, 2010; Wabnegger et al., 2021). This boom in research - largely in the field of psychology - on morbid curiosity and related psychological and behavioral phenomena implies that the construct is interesting, relevant, and in need of theoretical clarification and an appropriate assessment tool. 


\section{PSYCHOLOGY OF MORBID CURIOSITY}

The lack of adoption of the CAME scale may be due, in part, to the scale itself. The CAME scale is unidimensional and has not been extensively validated either internally or externally.

Moreover, it is unclear what qualifies as a morbid event; morbid events and violence appear to be conflated in the paper without any elaboration on the construct of morbid events or morbid curiosity. Most questions on the CAME scale are about witnessing violence, which may only be one part of morbid curiosity. Questions about horror movies are included in the scale, and attendance at horror films was used in the study as a point of comparison, yet horror films contain much more than violence. While violence does feature prominently in many horror films, the main feature of a horror film may be psychological thrills, body disgust, or supernatural phenomena rather than violence per se. Yet, even in the absence of violence, interest in a psychological thriller or a ghost story might be considered a morbid curiosity. Likewise, curiosity about the occult, a major disease, or the mind of a serial killer may also be considered morbid curiosity. Thus, morbid curiosity is not equivalent with interest in seeing violence. The focus on violence in the CAME scale may in part explain why it has not achieved widespread use despite the increase in research on morbid curiosity. Therefore, a more robust conceptualization of morbid curiosity is needed.

The descriptor "morbid" suggests that death plays a central role in defining the object of curiosity. However, death itself does not need to be the focus of the curiosity. Indeed, it may not make sense for something as broad and abstract as death to be the object of curiosity. Rather, the factors that lead to death might be the objects of morbid curiosity. To the extent that morbid curiosity (or any psychological trait) is an aspect of cognition that has been shaped by evolution, then it would make sense for natural selection to act not on the broad and abstract concept of 


\section{PSYCHOLOGY OF MORBID CURIOSITY}

death, but instead on more specific socioecological problems related to death (e.g., see Kirkpatrick \& Navarrete, 2006 and Navarrete \& Fessler, 2005).

Let us consider an analogy with reproduction and sexual desire. While the ultimate outcome (production of offspring and passing on of genes) is what "matters" for the evolution of reproductive behavior, it is the pathway to this outcome (sex) that is the object of desire. Similarly, the ultimate outcome of a morbid event (death) is what matters, but the pathway to it (a dangerous phenomenon) is the object of curiosity. In other words, death itself is not necessarily what we are curious about; we are curious about the things that lead to death. Understood in this way, morbid curiosity may be defined as an interest in phenomena perceived as dangerous or threatening.

While seeking out dangerous information probably is influenced by sensation seeking as Zuckerman and Litle suggest, it seems unlikely that sensation seeking is the core of morbid curiosity. A sensation-seeking account of morbid curiosity would predict that more intense images would capture more curiosity. However, Oosterwijk (2017) found no relationship between the rated intensity of an image and participant choice to investigate that image, casting some doubt on the central role of sensation seeking in explaining morbid curiosity. While rated intensity did not influence choice, the nature of the negative stimulus (e.g., violence in social context vs. graphic physical harm) did influence the likelihood of it being chosen over neutral or positive stimuli. Oosterwijk also reported extensive individual variation in how often participants chose to view the morbid stimuli. Oosterwijk's findings suggest that morbid curiosity is more 


\section{PSYCHOLOGY OF MORBID CURIOSITY}

than just trait sensation seeking and may be best understood as a multi-factor construct with extensive inter-individual variation.

I argue that morbid curiosity drives individuals to learn about aspects of life that are perceived to be dangerous, whether it is dangerous people, violent interactions, violations of the body, or the cognitively co-opted "dangers" of supernatural phenomena. When a dangerous phenomenon is perceived to be near or impending curiosity may spike in order to gather information about the dangerous phenomenon. By learning about the dangerous and disgusting factors associated with death, one can learn to avoid the negative outcomes associated with those factors. Too much avoidance of dangerous or disgusting factors associated with death could lead to ignorance about ecologically important aspects of the world and would be maladaptive in many cases. However, like other traits, individual differences exist in the extent to which one is curious about the dangerous aspects of life.

\section{The Current Research}

If morbid curiosity is to be properly studied as an individual difference in psychology, then a reliable scale that assesses trait morbid curiosity is needed. The goal of the current research was to create a robust personality instrument for morbid curiosity, evaluate which personality and individual differences are most strongly correlated with morbid curiosity, and assess the degree to which individuals are morbidly curious in a behavioral task. In Studies 1a-d, the Morbid Curiosity Scale (MCS) was created and the factor structure of the construct was evaluated $\left(\mathrm{n}_{\text {total }}=1040\right)$. The factor structure of the MCS was confirmed in Study 2 on a new sample of participants $(n=330)$. Participants in Study 2 also completed a series of personality questionnaires to assess the convergent and discriminant validity of the MCS and investigate the 
PSYCHOLOGY OF MORBID CURIOSITY

personality correlates of morbidly curious people. Study $3(n=317)$ demonstrated that trait morbid curiosity is stable over 4-6 weeks and that morbidly curious individuals prefer movies where threat is a central theme. Study $4(n=137)$ was test of the predictive power of the MCS in a behavioral task. Participants completed the MCS followed by a computerized choice task where they chose to view either morbid or non-morbid stimuli based on limited information (i.e., brief flashing of competing images and vague descriptions). Together, these four studies delineate the broader psychological nature of morbid curiosity, its relationship to personality and behavior, and provide researchers with a robust 24-item instrument for measuring trait morbid curiosity.

\section{Research Ethics Approval}

The Institutional Review Board for the Social Science Division at the University of Chicago approved procedures of all studies.

\section{Study 1}

\section{Study 1 Method}

\section{Participants}

The morbid curiosity scale was developed across four factor analysis studies. The fourth and final iteration is described here; the full description of the first three iterations and rationale for item generation can be found in the Supplementary Material (Studies 1a-1c). For the fourth iteration of the scale, 20 items from the previous version were included alongside nine new items. Based on factor analysis from the previous versions of the scale, items were chosen for the fourth version that fit into one of four categories: minds of dangerous people, body violations, 


\section{PSYCHOLOGY OF MORBID CURIOSITY}

interpersonal violence, and supernatural danger. US adults $(\mathrm{n}=283 ; 123$ female $)$ were recruited through MTurk and an online participant recruitment portal at the University of Chicago $(\mathrm{n}=$ 112; 79 female) for a study on personality and curiosity. Ten participants were removed from analysis for nonsense answers to an open-ended attention check $\left(\mathrm{n}_{\text {total }}=385\right)$. All participants completed the task online at their convenience. MTurk eligibility was contingent upon being 18 or older, having completed at least 100 tasks, having a 96\% or higher approval rate, and fluency in English. Eligibility for the university sample was contingent upon being 18 or older and fluency in English.

Participant age ranged between 19 and $77\left(M_{\text {age }}=34\right)$. Of those who reported their race $(\mathrm{n}=$ 379), $67 \%$ reported their race as White/Caucasian, 13\% as Asian, 10\% as Black/African American, and 8\% as Other/Multiracial. Since online and student samples are often used in psychological research, combining the two is one way to better capture generalizability in participant samples typically used in psychology experiments and increase sample size. Sample size was determined by funding and number of participants recruited by the end of the academic quarter. While there is no official manner by which sample size should be determined for exploratory factor analysis, the final sample of 385 participants and item pool of 29 items exceeds common heuristics used to determine sample size for factor analysis, including a sample size of greater than 300 (Comrey and Lee, 1992) and a subject-to-item ratio of 10:1 (Everitt, 1975; Nunnally, 1978).

Participants rated the extent to which they agreed or disagreed with the 29 proposed items of the Morbid Curiosity Scale on a 6-point scale $(1=$ Strongly disagree to $6=$ Strongly agree $)$. 
PSYCHOLOGY OF MORBID CURIOSITY

Exploratory factor analysis (EFA) was used to analyze the underlying factors in the Morbid Curiosity Scale using the psych package in R (Revelle, 2018).

\section{Study 1 Results and Discussion}

Nine outliers were detected using Mahalanobis distance $\left(X^{2}(29)=58.30\right)$ and they were removed from further analysis $\left(\mathrm{n}_{\text {final }}=376\right)$. Data were inspected for multivariate assumptions (normality, linearity, homogeneity, and homoscedasticity) to ensure they were appropriate for EFA.

Bartlett's test indicated that the data would benefit from factor analysis $\left(X^{2}(406)=6773.75, p<\right.$ $.001)$ and the Kaiser-Meyer-Olkin (KMO) test indicated sampling adequacy for EFA $(M S A=$ 0.93).

A parallel analysis showed that the first four factors had eigenvalues of 10.21, 2.12, 1.87, and 1.35 , respectively, while the fifth factor had an eigenvalue of 0.26 . The first five randomly generated eigenvalues were $0.73,0.50,0.44,0.38$, and 0.34 , respectively. Thus, the parallel analysis suggested that a four-factor model of morbid curiosity was appropriate. Visual inspection of a scree plot supported the four-factor solution (Supplementary Figure 1). Maximum likelihood estimation was used with direct oblimin (oblique) rotation to examine factor structure. Using a factor loading criterion of .30, the model achieved simple structure with each item loading on only one factor.

Item loadings ranged from .36 to .89 , with an average loading of .72 (Supplementary Figure 2). Item S8, which was about belief in ghosts/spirits, was removed because it was less related to the other questions which are about the interestingness of morbid phenomena rather than the reality 
PSYCHOLOGY OF MORBID CURIOSITY

of morbid phenomena. The lowest performing items on each subscale tended to be the reverse coded items (B3, S4, V1). Though the items cross-loaded below the pre-determined cutoff of .30, these items were removed due to minor cross-loading $(.17-.27)$ and lower performance compared to other items. The items on the minds of dangerous people subscale were all adequate, but one item (M1) was also removed to reduce redundancy in that subscale. See Supplementary Table 4 for the five items that were removed.

EFA was conducted on the reduced pool of items $(n=24)$. The scale achieved stable structure with factor loadings ranging from .45 to $.92(M=.73)$. Indices of fit suggested adequate fit with RMSEA at $.067(90 \%$ CI[.060, .074]), SRMR at .03, CFI at .95, and TLI at .92. The scale as a whole demonstrated excellent internal reliability (Cronbach's $a=.94)$, as did each subscale $(a=$ .87-.92; Table 1). Factors correlated with one another between .40 and .47 , and the average interitem correlation for the entire scale was .38. The averages for each subscale reported in Table 1. The mean scores for each factor were: minds of dangerous people $M=3.83(S D=1.30)$, supernatural danger $M=3.18(S D=1.34)$, interpersonal violence $M=3.17(S D=1.22)$, body violation $M=2.82(S D=1.27)$.

\section{Table 1}

Factor loadings of the 24 items in the Morbid Curiosity Scale

\begin{tabular}{|c|c|c|c|c|}
\hline \multirow[b]{2}{*}{ Items } & \multicolumn{4}{|c|}{ Factor Loadings } \\
\hline & $\begin{array}{c}1 \\
\text { Minds } \\
\end{array}$ & $\begin{array}{c}2 \\
\text { Supernatural } \\
\end{array}$ & $\begin{array}{c}3 \\
\text { Body } \\
\end{array}$ & $\begin{array}{c}4 \\
\text { Violence } \\
\end{array}$ \\
\hline $\begin{array}{l}\text { 2. If a head transplant was possible, I would } \\
\text { want to watch the procedure. (B1) }\end{array}$ & 0.00 & 0.07 & 0.75 & 0.05 \\
\hline $\begin{array}{l}\text { 6. I would be curious to see how an autopsy is } \\
\text { performed. (B2) }\end{array}$ & 0.10 & -0.08 & 0.80 & -0.03 \\
\hline $\begin{array}{l}\text { 10. I am interested in seeing how limb } \\
\text { amputation works. (B4) }\end{array}$ & -0.02 & -0.03 & 0.92 & -0.01 \\
\hline
\end{tabular}


14. I would like to see how bodies are prepared for funerals. (B5)

18. I think the preservation of bodies, like in taxidermy or mummification, is interesting. (B6)

22. I am curious what the deadliest toxin in the world would do to the body. (B7)

3. I am curious about crime and enjoy reading detailed news accounts about murders and other violent crimes. (M2)

7. I would be interested in watching a documentary on motives behind real murders. (M3)

11. My favorite part of a crime show is learning about why the killer did what he did. (M4)

15. I would be interested in watching an interview with an imprisoned serial killer talking about his crimes. (M5)

19. Being a criminal profiler who studies the personality of murderers would be an interesting job. (M6)

23. I am curious about the minds of violent people. (M7)

4. I think the supernatural is an interesting topic. (S1)

8. I would be interested in attending or watching a video of an exorcism. (S2)

12. I find the Occult interesting. (S3)

16. A documentary on Voodoo would interest me. (S5)

20. I am curious how a Ouija board works. (S6)

24. I think witchcraft would be an interesting topic to learn about. (S7)

1. If I lived in Medieval Europe, I would be interested in attending a public execution. (V2)

5. If I lived in Ancient Rome, I would be interested in attending a gladiatorial fight. (V3)

9. If I saw a street fight break out, and knew I could not intervene, I would try to watch it. (V4)
0.70

0.88

$\begin{array}{llll}0.01 & 0.10 & \mathbf{0 . 7 1} & -0.01\end{array}$

$\begin{array}{llll}0.04 & 0.23 & \mathbf{0 . 5 1} & 0.09\end{array}$

$\begin{array}{llll}\mathbf{0 . 7 3} & 0.02 & -0.02 & -0.02\end{array}$

$\begin{array}{llll}\mathbf{0 . 8 5} & 0.02 & -0.05 & 0.05\end{array}$

$\begin{array}{llll}\mathbf{0 . 7 5} & 0.04 & 0.08 & -0.08\end{array}$

$\begin{array}{llll}\mathbf{0 . 8 4} & 0.00 & -0.01 & 0.03\end{array}$

$\begin{array}{llll}0.02 & \mathbf{0 . 7 2} & -0.11 & 0.04\end{array}$

$\begin{array}{llll}-0.07 & \mathbf{0 . 5 9} & 0.21 & 0.19\end{array}$

$\begin{array}{llll}0.00 & \mathbf{0 . 7 6} & 0.04 & 0.03\end{array}$

$\begin{array}{llll}0.07 & \mathbf{0 . 8 0} & 0.01 & 0.01\end{array}$

$\begin{array}{llll}0.00 & \mathbf{0 . 7 3} & 0.08 & -0.09\end{array}$

$\begin{array}{llll}0.02 & \mathbf{0 . 9 1} & -0.04 & -0.02\end{array}$

$\begin{array}{llll}-0.09 & 0.09 & 0.29 & \mathbf{0 . 5 6}\end{array}$

$\begin{array}{llll}-0.03 & -0.06 & -0.02 & \mathbf{0 . 8 8}\end{array}$

$\begin{array}{llll}0.09 & 0.06 & 0.03 & \mathbf{0 . 5 8}\end{array}$ 
PSYCHOLOGY OF MORBID CURIOSITY

13. I would be curious enough to watch a duel if I lived in the Wild West. (V5)

$\begin{array}{llll}0.08 & -0.02 & -0.03 & \mathbf{0 . 8 1}\end{array}$

17. I prefer violent movies and TV shows to be uncensored. (V6)

$\begin{array}{llll}0.06 & 0.15 & 0.03 & \mathbf{0 . 5 5}\end{array}$

21. I am curious what a battle looked like in the Middle Ages. (V7)

$\begin{array}{llll}0.00 & 0.06 & -0.03 & \mathbf{0 . 7 1}\end{array}$

Cronbach's alpha

.92

.90

.55

.87

.89

Interitem Correlation $(M)$

.64

Percent of explained variance

$29 \%$

$26 \%$

.48

.53

Percent of explained variance

In summary, iterative exploratory factor analysis was used to investigate the factor structure of morbid curiosity. A final four-factor structure emerged consisting of 1) Minds of Dangerous People, 2) Supernatural Danger, 3) Interpersonal Violence, and 4) Body Violation. Central to each of these factors is interest in learning about dangerous or threatening phenomena. For example, interviewing a serial killer, attending an exorcism, watching a duel, and observing an autopsy all allow for an observer to learn about phenomena that are dangerous. Morbid curiosity about certain factors, such as Minds of Dangerous People, may be more universally common due to the relative lack of aversive factors like disgust that are more common in other factors.

The four-factor scale demonstrated excellent internal reliability, adequate fit across several indices, a stable factor structure with no items loading on more than one factor greater than .30 , and all items loading onto their factor at .45 or higher. Each factor explained a similar amount of variance, ranging from $22 \%$ to $29 \%$. In order to confirm the factor structure of the scale, a new sample of participants was recruited in Study 2. Participants in Study 2 also completed additional personality questionnaires so that the convergent validity, discriminant validity, and correlations between trait morbid curiosity and other individual differences could be assessed. 
PSYCHOLOGY OF MORBID CURIOSITY

\section{Study 2}

In Study 2, the factor structure of the Morbid Curiosity Scale (MCS) was verified using confirmatory factor analysis on a new sample of participants. The convergent and discriminant validity of the MCS was also evaluated by examining correlations between scores on the MCS on other measures of individual difference. If morbid curiosity is, at its core, a curiosity about dangerous phenomena, then it should 1) correlate positively with other measures of approach tendencies (e.g., curiosity), 2) correlate positively with an interest in media that portrays threats (e.g., horror media and violent media), and 3) correlate negatively with measures of threat avoidance (e.g., disgust sensitivity). Because psychopathy has been found to decrease threat avoidance (e.g., von Borries et al., 2012), the relationship between morbid curiosity and psychopathy was also explored. Finally, the relationship between HEXACO and the MCS and chronotype and the $\mathrm{MC}$ were investigated to further explore the psychological correlates of morbid curiosity.

\section{Study 2 Method}

\section{Participants}

US participants $(n=340)$ were recruited through Prime Panels for a study on personality and curiosity. Prime Panels is an online recruiting service that utilizes a compilation of online research panels and pre-screened participants, resulting in more nationally representative demographics, more experimentally naïve participants, and high-quality participant data (Chandler, Rosenzweig, Moss, Robinson, \& Litman, 2019). Ten participants failed attention checks and were removed from further analysis, leaving a total of 330 (157 female) participants. 
PSYCHOLOGY OF MORBID CURIOSITY

Participant age ranged between 18 and $96\left(M_{\text {age }}=42\right)$. Self-reported race was approximately 83.5\% White/Caucasian, 12\% Black/African American, 1.5\% Asian, 1.5\% Native American, and $2 \%$ Other/Multiracial.

\section{Confirmatory Factor Analysis}

Confirmatory factor analysis was conducted using maximum likelihood estimation and the Lavaan package for R. Five different indices of fit - CFI, TLI, RMSEA, SRMR, and $\chi^{2}$ were used in assessing the factor structure.

\section{Measures}

In addition to the 24-item Morbid Curiosity Scale, participants completed the FiveDimensional Curiosity Scale Revised (Kashdan, Disabato, Goodman, \& McKnight, 2020). The revised scale (5DCR) assesses curiosity along the dimensions of joyous exploration, deprivation sensitivity, stress tolerance, thrill seeking, and social curiosity (separated into overt and covert social curiosity in the revised scale). Additionally, participants completed the 60-item HEXACO personality scale, which assesses personality along the dimensions of honesty-humility, emotionality, extraversion, agreeableness, conscientiousness, and openness (Ashton \& Lee, 2009). Participants completed the Psychopathic Personality Inventory Revised short-form (PPISF; Lilienfeld \& Hess, 2001). The PPI-SF is a well-validated and widely used measure of psychopathy that includes several subscales, including Machiavellian egocentricity, social potency, fearlessness, cold-heartedness, impulsive non-conformity, carefree non-planfulness, blame externalization, and stress immunity (Kastner, Sellbom, \& Lilienfeld, 2012). The Disgust Scale Revised (DSR), which includes subscales on core disgust, animal reminder, and contamination disgust, was also administered to participants (Haidt, McCauley, \& Rozin, 1994; 
PSYCHOLOGY OF MORBID CURIOSITY

revised by Olatunji et al., 2007). Participants' chronotype was also assessed using the Reduced Morningness-Eveningness Questionnaire (Adan, \& Almirall, 1991). Finally, participants reported basic demographics and how often they engaged with violent media and horror media per week.

\section{Study 2 Results and Discussion}

\section{Confirmatory Factor Analysis}

The four-factor model demonstrated adequate indices of fit: $\chi^{2}(246)=778.23, \mathrm{p}<.001$; $\mathrm{RMSEA}=.081,90 \% \mathrm{CI}[.075, .087]) ; \mathrm{SRMR}=.06, \mathrm{CFI}=.92$; and TLI $=.91$. The four-factor model also performed better than a one-factor model $\chi^{2}(252)=1643.67, \mathrm{p}<.001$; RMSEA $=.13$, $90 \% \mathrm{CI}[.123, .135]) ; \mathrm{SRMR}=.07, \mathrm{CFI}=.78$; and TLI $=.76$. The obtained indices of fit values of the four-factor model were similar to other well-validated curiosity scales (e.g., Kashdan, Disabato, Goodman, \& McKnight, 2020) and meet common benchmarks of good model fit (Kenny, 2015). As a whole, CFA on this sample of participants supports the 24-item Morbid Curiosity Scale presented in Study 1.

\section{Personality Traits}

Zero-order correlations between the MCS and the other scales are presented in Table 2. Since sex was a variable of interest, two participants were removed from analysis for reporting a sex other than male or female, leaving a total of 328 participants for analysis. The correlations in this sample suggest that the MCS is measuring a unique aspect of personality that is separate from thrill-seeking, other aspects of curiosity, horror media use, and disgust sensitivity. 
PSYCHOLOGY OF MORBID CURIOSITY

Table 2

Study 2 Zero-Order Correlations with Morbid Curiosity and Morbid Curiosity Subscales

\begin{tabular}{|c|c|c|c|c|c|}
\hline $\begin{array}{l}\text { Personality / Individual } \\
\text { Difference Measure }\end{array}$ & $\begin{array}{l}\text { Violence } \\
\text { Subscale }\end{array}$ & $\begin{array}{c}\text { Body } \\
\text { Subscale }\end{array}$ & $\begin{array}{c}\text { Minds } \\
\text { Subscale }\end{array}$ & $\begin{array}{c}\text { Supernatural } \\
\text { Subscale }\end{array}$ & $\begin{array}{c}\text { Morbid } \\
\text { Curiosity }\end{array}$ \\
\hline Horror Media Use & .56 & .50 & .43 & .51 & .56 \\
\hline PPI Rebel & .58 & .53 & .36 & .49 & .55 \\
\hline PPI Fearlessness & .54 & .53 & .33 & .37 & .50 \\
\hline PPI Total & .55 & .50 & .32 & .40 & .50 \\
\hline PPI Machiavellianism & .51 & .50 & .32 & .41 & .49 \\
\hline FDC Thrill Seeking & .49 & .50 & .34 & .41 & .49 \\
\hline Violent Media Use & .51 & .41 & .35 & .41 & .47 \\
\hline PPI Social Potency & .31 & .37 & .26 & .26 & .34 \\
\hline FDC Covert Social Curiosity & .30 & .33 & .25 & .31 & .34 \\
\hline FDC Joyous Exploration & .20 & .30 & .28 & .25 & .29 \\
\hline FDC Deprivation Sensitivity & .22 & .30 & .25 & .25 & .29 \\
\hline PPI Blame Externalization & .30 & .26 & .20 & .25 & .29 \\
\hline FDC Over Social Curiosity & .20 & .27 & .26 & .28 & .28 \\
\hline Extraversion & .14 & .19 & .12 & .08 & .15 \\
\hline Openness & .04 & .10 & .07 & .22 & .12 \\
\hline Chronotype & .08 & .09 & -.05 & .09 & .06 \\
\hline Agreeableness & .00 & .08 & -.01 & -.06 & .01 \\
\hline DSR Contamination & .00 & -.03 & -.03 & -.07 & -.03 \\
\hline Emotionality (Neuroticism) & -.12 & -.04 & .01 & .02 & -.04 \\
\hline PPI Carefree Nonplanfulness & .00 & -.08 & -.07 & -.05 & -.06 \\
\hline FDC Stress Tolerance & -.05 & -.08 & -.04 & -.08 & -.07 \\
\hline PPI Coldheartedness & -.03 & -.13 & -.18 & -.10 & -.12 \\
\hline PPI Stress Immunity & -.12 & -.16 & -.09 & -.18 & -.16 \\
\hline DSR Total & -.16 & -.20 & -.17 & -.15 & -.19 \\
\hline DSR Animal Reminder & -.14 & -.22 & -.18 & -.15 & -.20 \\
\hline Conscientiousness & -.28 & -.20 & -.10 & -.18 & -.22 \\
\hline DSR Core & -.21 & -.22 & -.17 & -.16 & -.22 \\
\hline Age & -.30 & -.30 & -.16 & -.23 & -.28 \\
\hline Sex & -.45 & -.34 & -.20 & -.26 & -.35 \\
\hline Honesty-Humility & -.45 & -.40 & -.26 & -.39 & -.42 \\
\hline
\end{tabular}

Note. Sex was coded as 1 for male and 2 for female, so negative correlations indicated male-skewed correlations. Scale abbreviations are as follows: PPI - Psychopathic Personality Inventory short form revised; FDC - FiveDimensional Curiosity Scale; DSR - Disgust Sensitivity Revised. 


\section{PSYCHOLOGY OF MORBID CURIOSITY}

Less than half the variance in MCS scores was explained (multiple $r^{2}=.48$, adjusted $r^{2}=.44$ ) in a regression model that included every administered subscale, age, and sex as fixed effects. Nonsignificant predictors were removed one at a time based on the highest $p$-value until only significant predictors remained. A reduced regression model was conducted with the eight significant variables that remained from the full model (Table 3). At the core of these traits is the propensity to be rebellious (honesty-humility, rebellious nonconformity), unafraid of death or reminders of it (animal reminder disgust, PPI fearlessness), experiencing arousal from stress (stress immunity), and an interest in people (overt social curiosity). The reduced model predicted about $44 \%$ of the variance in morbid curiosity (multiple $r^{2}=.45$, adjusted $r^{2}=.44$ ). In other words, defying social conventions, being interested in what makes people tick, and not fearing the certainty of death were good predictors of being high in trait morbid curiosity. These traits may provide the motivational push required for an individual to become curious about and investigate dangerous circumstances.

In sum, Study 2 provides further validity to the factor structure and construct of morbid curiosity as an individual difference. Convergent validity was confirmed through positive associations between morbid curiosity and individual differences such as horror media use, thrill-seeking, and social curiosity. Divergent validity was established through negative correlations with age, core disgust, animal reminder disgust, and honesty-humility. Finally, the inability of a large repertoire of traits to explain even half the variance in morbid curiosity suggests that the Morbid Curiosity Scale is measuring a distinct individual difference that is not captured by general personality, disgust, psychopathy, or general curiosity. 
PSYCHOLOGY OF MORBID CURIOSITY

Table 3

Study 2 Reduced Regression Model for Individual Differences that Predict Morbid Curiosity

\begin{tabular}{lcccc}
\hline \multicolumn{1}{c}{$\begin{array}{c}\text { Personality / Individual } \\
\text { Difference Measure }\end{array}$} & Estimate & SE & $\boldsymbol{t}$ & $\boldsymbol{p}$ \\
\hline FDC Overt Social Curiosity & 0.22 & 0.05 & 4.39 & $<.001$ \\
Honesty-Humility & -0.26 & 0.11 & -2.45 & .015 \\
Animal Reminder Disgust & -0.31 & 0.07 & -4.62 & $<.001$ \\
PPI Fearlessness & 0.03 & 0.01 & 2.17 & .031 \\
PPI Rebellious Nonconformity & 0.06 & 0.01 & 3.99 & $<.001$ \\
PPI Stress Immunity & -0.04 & 0.01 & -2.81 & .005 \\
Sex & -0.42 & 0.13 & -3.32 & .001 \\
Age & -0.01 & 0.00 & -2.14 & .033 \\
& & & \\
Note: PPI Stress Immunity can be described as the absence of arousal in stressful situations (Kastner \& \\
Selbom, 2012). Importantly, a complete lack of arousal in stressful situations would be unmotivating. Indeed, \\
enjoyment of fearful situations occurs not when there is a lack of arousal, but rather an optimal amount of \\
arousal (Clasen et al., 2019; Andersen et al., 2020). Corroborating this, PPI Stress Immunity was not \\
correlated with thrill-seeking in this study $(r=-.03, p=.587)$.
\end{tabular}

\section{Study 3}

Studies 1 and 2 examined and confirmed the factor structure of the 24-item Morbid Curiosity Scale and identified personality traits associated with morbid curiosity. The aim of Study 3 was to test the stability of morbid curiosity across time assess its relationship to media preferences while controlling for other aspects of personality and individual differences. In particular, I hypothesized that morbid curiosity would predict fandom of genres where a threatening or dangerous phenomenon is central to the story (e.g., horror, crime, and thriller) and should be unrelated to genres where threat is not central to the story (e.g., romance and comedy). 
PSYCHOLOGY OF MORBID CURIOSITY

\section{Study 3 Method}

\section{Participants}

US participants $(\mathrm{n}=322 ; 181$ female) were recruited through Prolific for a larger study on Personality, Media, and Current Events. Only questions pertaining to morbid curiosity and media preferences were analyzed in this study. Five participants failed attention checks and were removed from further analysis, leaving a total of 317 participants. Participant age ranged between 18 and $66\left(M_{\text {age }}=31\right)$.

\section{Confirmatory Factor Analysis}

Confirmatory factor analysis was conducted using maximum likelihood estimation and the Lavaan package for R. Five different indices of fit - CFI, TLI, RMSEA, SRMR, and $\chi^{2}$ were used in assessing the factor structure.

\section{Measures}

Participants completed the 24-item Morbid Curiosity Scale, the Ten-Item Personality Inventory (TIPI), reported their age and sex, and answered a series of questions about their media preferences. Participants were asked to what extent they agreed (7-point scales, strongly disagree to strongly agree) with each of 10 statements about genre fandom. The statements were

phrased: "I would consider myself a fan of movies and TV shows." The genres included horror, zombie, psychological thriller, supernatural, apocalyptic/post-apocalyptic, science fiction, alien-invasion, crime, comedy, and romance. 
PSYCHOLOGY OF MORBID CURIOSITY

\section{Study 3 Results and Discussion}

\section{Confirmatory Factor Analysis}

The Morbid Curiosity Scale demonstrated strong internal reliability $(a=.92)$ and a Shapiro-Wilk normality test indicated that responses were normally distributed $(p=.075$; Supplementary Figure 3) The four-factor model demonstrated adequate indices of fit: $\chi^{2}(246)=$ $555.21, \mathrm{p}<.001 ; \mathrm{RMSEA}=.064,90 \% \mathrm{CI}[.057, .071]) ; \mathrm{SRMR}=.066, \mathrm{CFI}=.93 ;$ and $\mathrm{TLI}=.92$. The indices of fit values were similar or even slightly better than those in Study 2, suggesting the factor structure holds up well. CFA on this sample of participants further supports the validity 24-item Morbid Curiosity Scale.

\section{TIPI and Morbid Curiosity}

A regression model was conducted with each of the big five dimensions from the TIPI as predictors and morbid curiosity as the outcome. Agreeableness was the only significant predictor of morbid curiosity in the model $(\beta=-.13, S E=0.04, p=.005)$. The overall $\mathrm{r}^{2}$ for the model was .04 , suggesting that the big five personality traits account for very little variation in trait morbid curiosity (Supplementary Table 5).

\section{Genre Fandom}

Regressions were conducted for trait morbid curiosity and each genre question while controlling for sex, age, income, and TIPI scores (Table 4). Trait morbid curiosity predicted alien-invasion, apocalyptic, crime, horror, supernatural, thriller, and zombie genre fandom. As expected, trait morbid curiosity was unrelated to comedy and romance genre fandom. Interestingly, morbid curiosity was also unrelated to science fiction fandom broadly but was 
PSYCHOLOGY OF MORBID CURIOSITY

related to alien-invasion film fandom - a science fiction sub-genre where an external threat is a central theme.

\section{Table 4}

Morbid Curiosity and Film Genre Fandom Controlling for Age, Sex, Income, and Big Five Personality

\begin{tabular}{lcccc}
\hline Genre & Estimate & $\boldsymbol{S E}$ & $\boldsymbol{t}$ & $\boldsymbol{p}$ \\
\hline Alien-Invasion & 0.52 & 0.11 & 4.58 & $<.001$ \\
Apocalyptic & 0.67 & 0.11 & 6.07 & $<.001$ \\
Comedy & 0.15 & 0.08 & 1.87 & .062 \\
Crime & 0.93 & 0.09 & 9.93 & $<.001$ \\
Horror & 1.14 & 0.12 & 9.36 & $<.001$ \\
Romance & 0.00 & 0.11 & 0.03 & .977 \\
Science Fiction & 0.14 & 0.11 & 1.26 & .209 \\
Supernatural & 0.79 & 0.11 & 7.41 & $<.001$ \\
Thriller & 0.74 & 0.10 & 7.44 & $<.001$ \\
Zombie & 0.73 & 0.12 & 6.26 & $<.001$
\end{tabular}

\section{Test-Retest Reliability}

Four weeks after the initial study, participants were contacted again and asked to complete a second study. Though there is no agreed-upon time frame for test-retest reliability for stable traits, four weeks was chosen because it a stable trait should not change during this amount of time, but variation due to transient error (e.g., mood or other state psychological changes) could be accounted for. Participants were given 2 weeks to finish the second study. Of the 322 participants from the initial study, 257 completed the follow-up study. After removing participants who had failed attention checks in either study, 249 participants remained for testretest analysis. Participants' morbid curiosity scores from the follow-up study correlated strongly with scores from the first study $(r=.85, p<.001)$. Subscales also demonstrated strong test-retest 


\section{PSYCHOLOGY OF MORBID CURIOSITY}

reliability (minds: $r=.86$, supernatural: $r=.84$, body: $r=.81$, and violence: $r=.80$; all $p$ 's $<$ .001). A Shapiro-Wilk normality test indicated that responses to the Morbid Curiosity Scale retest were normally distributed ( $p=.093$; Supplementary Figure 4).

Study 3 tested the relationship between morbid curiosity and media preferences and provides additional support for morbid curiosity as a distinct individual difference. Trait morbid curiosity as measured by the Morbid Curiosity Scale was consistent over a 4-6-week period and the factor structure remained robust. Consistent with the theory that morbid curiosity is about motivation to learn about threat, trait morbid curiosity predicted fandom in film genres that center around a threat (e.g., horror, thriller, supernatural), and did not predict fandom in the genres that do not center around a threat (comedy and romance).

One particularly strong piece of evidence that morbid curiosity inspires individuals to learn about threat was the lack of a relationship between morbid curiosity and science fiction fandom broadly, but a very strong relationship between morbid curiosity and fandom for the threatcentered sub-genre of alien-invasion films. While some science fiction does center around threat, it is often more broadly centered around futuristic advances in science and technology. Thus, the core of science fiction is not about an external threat in the same way that it is for horror or thriller films. In sum, Study 3 adds to the convergent and divergent validity of the Morbid Curiosity Scale and the ability of morbid curiosity to account for media preferences beyond the effects of general personality and individual differences. 
PSYCHOLOGY OF MORBID CURIOSITY

\section{Study 4}

The results of Studies $1-3$ provide evidence that morbid curiosity is a measurable individual difference that impacts preferences and can be reliably assessed using the Morbid Curiosity Scale. The aim of Study 4 was to see if differences in trait morbid curiosity reliably predict morbidly curious behavior. To assess the extent to which scores on the Morbid Curiosity Scale predicted decisions to learn about morbid phenomena, participants completed a computerized choice task where they chose to gather additional information about either morbid or non-morbid stimuli based on limited information (i.e., brief flashing of competing images and vague descriptions).

\section{Study 4 Method}

\section{Participants}

Participants $\left(\mathrm{n}_{\text {total }}=144\right)$ were recruited though an online participant recruitment portal at the University of Chicago $(n=44)$ and Prolific $(n=100)$. Prolific eligibility was contingent upon being 18 or older, a US citizen, and speaking English as a first language. Eligibility for the

university sample was contingent upon being 18 or older and fluency in English. Six participants were removed due to incomplete data. Since sex was used in regression analysis, one participant was removed for selecting something other than male or female $\left(\mathrm{n}_{\text {final }}=137 ; 83\right.$ female $)$. Participant age ranged between 18 and $66\left(M_{\text {age }}=29.2\right)$.

\section{Procedure}

Participants completed the 24-item MCS followed by a computerized choice task similar to the one used in Oosterwijk et al. (2017). During the choice task, participants were presented 


\section{PSYCHOLOGY OF MORBID CURIOSITY}

with 32 trials. In the first 16 trials, two equally sized images were displayed side-by-side for 500 ms. After $500 \mathrm{~ms}$, the left side of the screen said "Press ' $Q$ ' to make the image on the left show up again for 4 seconds" and the right side of the screen said "Press 'P' to make the image on the right side of the screen show up again for 4 seconds." Participants made their selection and were allowed to view the image in the center of the screen for four seconds. Between each trial, participants saw a target in the center of the screen for $500 \mathrm{~ms}$ to help center their vision between the two images before stimuli were displayed.

For the second set of 16 trials, participants were first presented with two descriptions for an unlimited amount of time until a choice was made. Beneath the description on the left, participants were instructed to press Q if they wanted to see what the description described; beneath the description on the right, participants were instructed to press $\mathrm{P}$ to see what was described. The participant's choice remained on screen until the participant clicked "next." As with the images, each morbid description was paired with a closely matched control description. For example, one trial presented participants with the choice to view either a photo of a supposedly haunted building (supernatural) or a photo of a famous building (control). Based on the choice, participants would then see the photo of their choice. In some cases, descriptions described written text. For example, one trial presented participants with the choice to either read an excerpt of an interview with an astronaut about his job or to read an excerpt from an interview with an FBI profiler talking about his job. Photos were always paired with photos, and written descriptions were always paired with written descriptions. Each morbid image or description was always paired with the same closely matched control image or description. 


\section{PSYCHOLOGY OF MORBID CURIOSITY}

Presentation of pair order and which side the morbid image was presented on was randomized for all 32 trials such that morbid and control images were randomly displayed on either side of the screen. Participants were instructed that the task was not a reaction time test and that there were no right or wrong answers. Participants were asked to let their natural curiosity guide their selections. For analysis, the total number of morbid choices across both parts of the task was calculated. This was done to make the measure more robust to variations in presentation (visual flash vs semantic description).

\section{Study 4 Results and Discussion}

The average morbid curiosity score was $3.51(S D=0.96)$. A Shapiro-Wilk normality test indicated that responses were normally distributed $(p=.93)$. A paired t-test suggested that participants chose the non-morbid (17.3) stimuli slightly more often than the morbid (14.7) stimuli, $t(136)=2.01, p=.046, d=0.34)$. Participant age, sex, and scores on the MCS were regressed onto the number of morbid choices they made during the choice task. Scores on the MCS strongly predicted the number of morbid stimuli choices $(\beta=5.64, S E=0.48, p<.001$;

Figure 1). Neither age $(\beta=-0.06, S E=0.04, p=.134)$ nor $\operatorname{sex}(\beta=1.19, S E=0.94, p=.210)$ predicted the number of morbid stimuli chosen. 


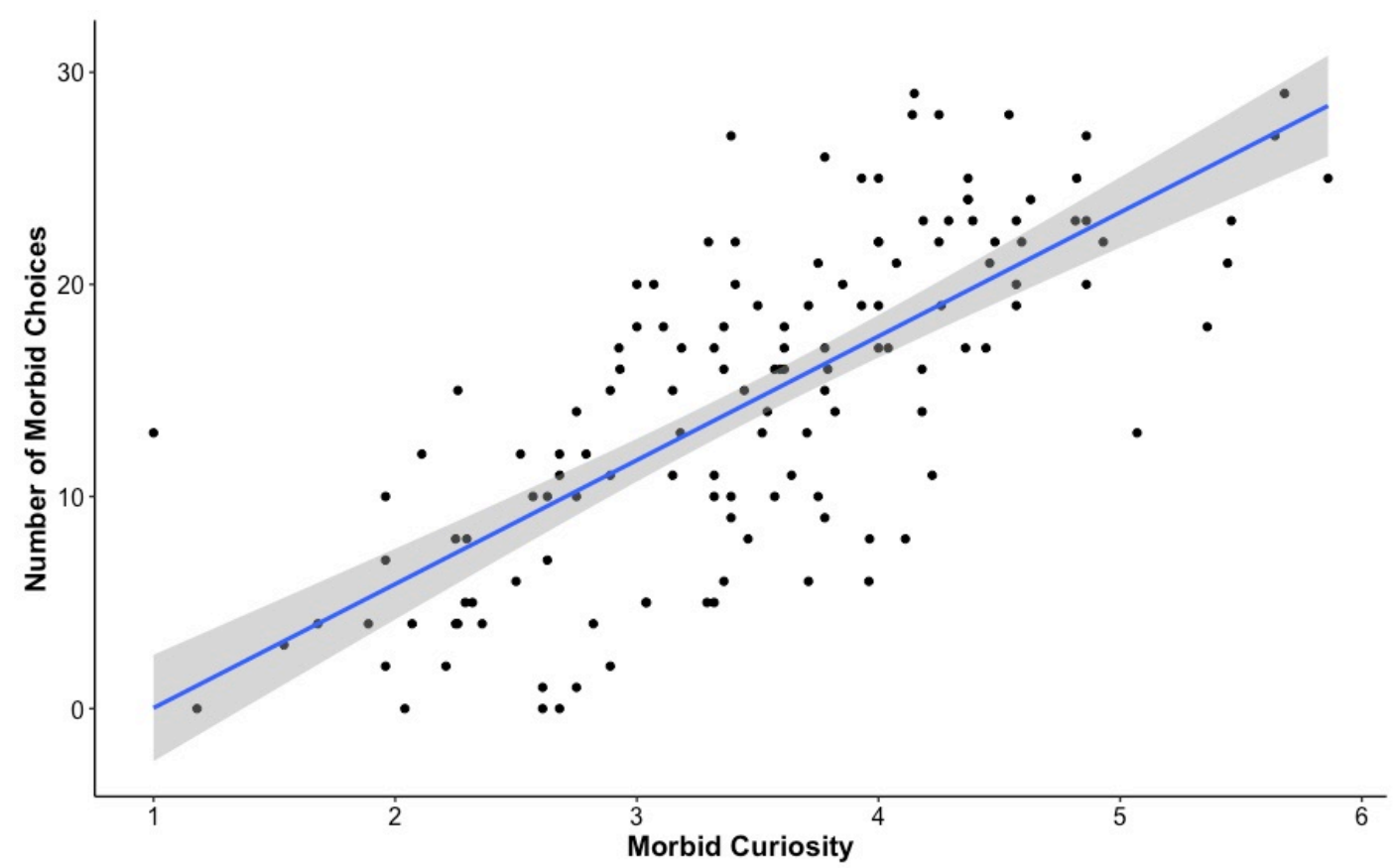

Figure 1. Correlation between scores on the Morbid Curiosity Scale and number of morbid stimuli chosen for inspection $\left(r=0.73, r^{2}=.53\right)$.

Study 4 was a simple test of whether or not the Morbid Curiosity Scale predicts behavior. On average, participants chose slightly fewer morbid stimuli than control stimuli. However, the average participant chose to further investigate the morbid stimuli about $46 \%$ of the time, suggesting that the average person possesses some degree of morbid curiosity. Additionally, variation in morbidly curious behavior was captured by scores on the Morbid Curiosity Scale. This study provided initial evidence that trait morbid curiosity can predict morbid information gathering behavior for visual and written stimuli.

\section{General Discussion}

Across four studies, this paper presents the first attempt to describe the psychological nature of morbid curiosity and assess individual differences in this trait. This was accomplished through the construction of the new Morbid Curiosity Scale (Study 1), assessing its validity 


\section{PSYCHOLOGY OF MORBID CURIOSITY}

(Study 2), and evaluating the extent to which it predicts morbidly curious preferences (Study 3) and behaviors (Study 4). While the four factors of the 24-item Morbid Curiosity Scale - minds of dangerous people, body violation, paranormal danger, and interpersonal violence - measure distinct facets of morbid curiosity, the underlying theme is a curiosity about dangerous phenomena.

In Study 2, morbid curiosity emerged as a distinct individual difference, correlated with but separate from related measures of curiosity and disgust sensitivity. The association of death with animal reminder disgust makes it a particularly interesting trait to analyze in relation to morbid curiosity. Citing Becker's (1973) argument that disgust serves to stave off thoughts of death, Rozin, Haidt, and McCauley (2008) argue that animal reminder disgust is about the threat of death to self-conscious beings. The factors that lead to death often inspire aversion, typically because they are dangerous. However, to completely avoid phenomena that could lead to death would produce dangerous naivety. Thus, it seems likely that there must also be a psychological mechanism that regulates interactions with dangerous phenomena and promotes information gathering about these phenomena when the benefits are perceived to be greater than the costs. Morbid curiosity is a promising candidate for the behavioral reflection of this psychological mechanism.

Crucially, there are individual differences in the degree to which dangerous information inspires curiosity. Perhaps one reason for the interindividual variation in morbid curiosity is that not every member of a group needs first-hand knowledge of a dangerous phenomenon in order to learn about it. Indeed, if a critical mass of individuals perpetuates information about dangerous 


\section{PSYCHOLOGY OF MORBID CURIOSITY}

material, it can quickly spread throughout the group. This is consistent with evidence suggesting that threat-related information is more readily accepted as true and that the sources that threat are perceived as competent (Boyer \& Parren, 2015; Fessler, Pisor, \& Navarrete, 2014; Hilbig, 2009). Combined with the inherent danger in being curious about dangerous situations and phenomena, the premium placed on dangerous information might result in only a small number of individuals being extremely morbidly curious. The rest of the population would only require a moderate degree of morbid curiosity - just enough to listen to those who are sharing the information - in order to benefit. In line with this, the results of Study 3 suggest that morbid curiosity is normally distributed in the population.

One area where morbid curiosity may play a particularly powerful role is in media preferences (Scrivner 2021; Scrivner et al., 2021). In Study 3, morbidly curious participants were more likely to be fans of movies and TV shows where threat was a central theme. Though threats in these movies and TV shows are not real, fictional stories can be valuable sources of information and learning (Clasen, Kjeldgaard-Christiansen, \& Johnson, 2018; Mar \& Oatley, 2008; Morin, Acerbi, \& Sobchuk, 2019; Scalise-Sugiyama, 2021). Consumers are sometimes conscious of this. For example, the desire for real-world knowledge has been found to be a motivating factor for engaging with violent media (Shaw, 2014; Bartsch et al., 2016). As noted by horror novelist Stephen King (1981), a good horror story uses fictional events to help readers understand their own real fears.

Study 4 provides empirical evidence that individuals vary with respect to morbidly curious behaviors and that this variation is captured by the Morbid Curiosity Scale. Individuals in Study 


\section{PSYCHOLOGY OF MORBID CURIOSITY}

4 who scored high in trait morbid curiosity preferred to further investigate information about morbid phenomena. The behavioral measure in Study 4 was a measure of epistemic morbid curiosity - i.e., gathering information via pictures or text, and it is unclear to what extent morbid curiosity predicts morbid behaviors that are more visceral. Presumably, a morbidly curious person would be more likely to not only prefer epistemic information about morbid objects, but also perhaps experiential or tactile information. However, the experiential or tactile information may only be preferred if it can provide additional knowledge that cannot be gleaned from a more distant method, such as visual inspection or reading. Future studies should attempt to distinguish between these different kinds of morbid curiosity.

The ability to measure individual differences in morbid curiosity may allow researchers to better understand which individuals would be likely to engage in certain kinds of morbid entertainment but not others. The lifestyle effects of being morbidly curious, and the extent to which morbid curiosity can change over time, will be interesting to explore in future studies. Understanding individual differences in morbid curiosity could be useful in a variety of fields, including tourism (e.g., dark tourism), media (e.g., news and movie preferences), clinical psychology (e.g., see Scrivner \& Christensen, 2021), criminology (e.g., in relation to psychopathy), and others.

\section{Limitations and Future Directions}

While this paper provides an important initial step in the study of the psychology of morbid curiosity, several questions remain. The four facets of morbid curiosity appear to target specific kinds of threats that humans face - the threat of violence, the threat of dangerous people, the threat of physical damage to the body, and the (cognitively co-opted) threat of the paranormal. 


\section{PSYCHOLOGY OF MORBID CURIOSITY}

However, threats can be somewhat subjective and encompass a wide variety of phenomena

Would an interest in predators, for example, be linked to morbid curiosity? What about weapons? While a gun could be considered a threat, it likely does not inspire morbid curiosity. However, a man holding a gun might inspire morbid curiosity, a man pointing a gun at another person probably would, and a man shooting another person almost certainly would. Likewise, a lion may not inspire morbid curiosity, but a lion attacking a person probably would, and a lion killing a person certainly would. As with the gun, the attractor would likely not be the lion, but the damage done to the body of the person it is attacking (i.e., body violation). More work needs to be done to detail the finer theoretical lines of what actually triggers morbid curiosity and how this relates to threat perception.

\section{Conclusion}

Across four experiments, this paper provides the groundwork for understanding the psychology of morbid curiosity. A novel and robust instrument for assessing individual differences in trait morbid curiosity was developed and validated. Personality correlates of morbid curiosity were assessed and the ability of the Morbid Curiosity Scale to predict behavior was demonstrated. In sum these studies revealed that while people on average possess some degree of morbid curiosity, substantial variation in morbid curiosity exists and is adequately captured by the Morbid Curiosity Scale.

\section{Data Availability}

The data that support the findings of this study are openly available on OSF at https://osf.io/3ms8p/?view_only=46e8ef680fac43358fc6445b2f9da3dd. 
PSYCHOLOGY OF MORBID CURIOSITY

\section{Funding}

This work was funded by the Neubauer Collegium for Culture and Society and the Department of Comparative Human Development at The University of Chicago.

\section{Declaration of interest statement}

The author declares no conflict of interest.

\section{Acknowledgements}

The author would like to thank Dario Maestripieri and Mathias Clasen for important feedback on earlier drafts of this manuscript.

\section{References}

Adan, A., \& Almirall, H. (1991). Horne \& Östberg morningness-eveningness questionnaire: A reduced scale. Personality and Individual differences, 12(3), 241-253. https://doi.org/10.1016/0191-8869(91)90110-W

Andersen, M., Schjoedt, U., Price, H., Rosas, F., Scrivner, C., \& Clasen, M. (2020). Playing with fear: A field study in recreational horror.

Armtrong, T., Engel, M., Press, T., Sonstroem, A., \& Reed, J. (2019). Fast-forwarding disgust conditioning: US pre-exposure facilitates the acquisition of oculomotor avoidance. Motivation and Emotion, 43(4), 681-695. https://doi.org/10.1007/s11031-019$\underline{09770-0}$ 


\section{PSYCHOLOGY OF MORBID CURIOSITY}

Ashton, M. C., \& Lee, K. (2009). The HEXACO-60: A short measure of the major dimensions of personality. Journal of personality assessment, 91(4), 340-345. https://doi.org/10.1080/00223890902935878

Bartsch, A., Mares, M. L., Scherr, S., Kloß, A., Keppeler, J., \& Posthumus, L. (2016). More than shoot-em-up and torture porn: Reflective appropriation and meaning-making of violent media content. Journal of Communication, 66(5), 741-765. https://doi.org/10.1111/jcom.12248

Bebbington, K., MacLeod, C., Ellison, T. M., \& Fay, N. (2017). The sky is falling: Evidence of a negativity bias in the social transmission of information. Evolution and Human Behavior, 38(1), 92-101. https://doi.org/10.1016/j.evolhumbehav.2016.07.004

Becker, E. (1973). The denial of death. Free Press.

Blaine, T., \& Boyer, P. (2018). Origins of sinister rumors: A preference for threat-related material in the supply and demand of information. Evolution and Human Behavior, 39(1), 67-75. https://doi.org/10.1016/j.evolhumbehav.2017.10.001

Boyer, P., \& Parren, N. (2015). Threat-Related Information Suggests Competence: A Possible Factor in the Spread of Rumors. PLOS ONE, 10(6), e0128421. https://doi.org/10.1371/journal.pone.0128421

Birmingham, E., Bischof, W. F., \& Kingstone, A. (2008). Social attention and real-world scenes: the roles of action, competition and social content. Quarterly Journal of Experimental Psychology , 61(7), 986-998. https://doi.org/10.1080\%2F17470210701410375

Bradley, M. M., Costa, V. D., \& Lang, P. J. (2015). Selective looking at natural scenes: Hedonic content and gender. International Journal of Psychophysiology: Official Journal of the International Organization of Psychophysiology, 98(1), 54-58. 


\section{PSYCHOLOGY OF MORBID CURIOSITY}

https://dx.doi.org/10.1016\%2Fj.ijpsycho.2015.06.008

Chandler, J., Rosenzweig, C., Moss, A. J., Robinson, J., \& Litman, L. (2019). Online panels in social science research: Expanding sampling methods beyond Mechanical Turk. Behavior research methods, 51(5), 2022-2038. https://psycnet.apa.org/doi/10.3758/s13428-019$\underline{01273-7}$

Clasen, M. (2012). Monsters evolve: A biocultural approach to horror stories. Review of General Psychology, 16(2), 222-229. https://doi.org/10.1037\%2Fa0027918

Clasen, M. (2017). Why horror seduces. Oxford University Press.

Clasen, M., Kjeldgaard-Christiansen, J., \& Johnson, J. A. (2020). Horror, personality, and threat simulation: A survey on the psychology of scary media. Evolutionary Behavioral Sciences. https://psycnet.apa.org/doi/10.1037/ebs0000152

Clasen, M., Andersen, M., \& Schjoedt, U. (2019). Adrenaline junkies and white-knucklers: A quantitative study of fear management in haunted house visitors. Poetics, 73, 61-71.

Comrey, A., \& Lee, H. (1992). A first course in factor analysis. Erlbaum.

Davis, H., \& McLeod, S. (2003). Why humans value sensational news. Evolution and Human Behavior, Vol. 24, pp. 208-216. https://doi.org/10.1016/s1090-5138(03)00012-6

End, A., \& Gamer, M. (2017). Preferential Processing of Social Features and Their Interplay with Physical Saliency in Complex Naturalistic Scenes. Frontiers in Psychology, 8, 418. https://dx.doi.org/10.3389\%2Ffpsyg.2017.00418

Everitt, B. S. (1975). Multivariate analysis: The need for data, and other problems. The British Journal of Psychiatry, 126(3), 237-240. https://doi.org/10.1192/bjp.126.3.237

Fessler, D. M. T., Pisor, A. C., \& Navarrete, C. D. (2014). Negatively-Biased Credulity and the Cultural Evolution of Beliefs. PLOS ONE, 9(4), e95167. 


\section{PSYCHOLOGY OF MORBID CURIOSITY}

\section{https://doi.org/10.1371/journal.pone.0095167}

Haidt, J., McCauley, C., \& Rozin, P. (1994). Individual differences in sensitivity to disgust: A scale sampling seven domains of disgust elicitors. Personality and Individual Differences, 16, 701-713. https://doi.org/10.1016/0191-8869(94)90212-7

Harrison, M. A., \& Frederick, E. J. (2020). Interested in serial killers? Morbid curiosity in college students. Current Psychology, 1-10. https://doi.org/10.1007/s12144-020-00896-w

Heath, C., Bell, C., \& Sternberg, E. (2001). Emotional selection in memes: the case of urban legends. Journal of Personality and Social Psychology, 81(6), 1028-1041. https://psycnet.apa.org/doi/10.1037/0022-3514.81.6.1028

Hilbig, B. E. (2009). Sad, thus true: Negativity bias in judgments of truth. Journal of Experimental Social Psychology, 45(4), 983-986. https://psycnet.apa.org/doi/10.1016/j.jesp.2009.04.012

Kashdan, T. B., Afram, A., Brown, K. W., Birnbeck, M., \& Drvoshanov, M. (2011). Curiosity enhances the role of mindfulness in reducing defensive responses to existential threat. Personality and Individual Differences, 50(8), 1227-1232. https://doi.org/10.1016/j.paid.2011.02.015

Kashdan, T. B., Disabato, D. J., Goodman, F. R., \& McKnight, P. E. (2020). The FiveDimensional Curiosity Scale Revised (5DCR): Briefer subscales while separating overt and covert social curiosity. Personality and Individual Differences, 157, 109836. https://doi.org/10.31219/osf.io/pu8f3

Kastner, R. M., Sellbom, M., \& Lilienfeld, S. O. (2012). A comparison of the psychometric properties of the psychopathic personality inventory full-length and short-form versions. Psychological Assessment, 24(1), 261. 


\section{PSYCHOLOGY OF MORBID CURIOSITY}

\section{https://psycnet.apa.org/doi/10.1037/a0025832}

Kenny, D. A. (2015). Measuring model fit. http://davidakenny.net/cm/fit.htm.

Kerr, M. (2015). Scream: Chilling adventures in the science of fear. PublicAffairs.

Kerr, M., Siegle, G. J., \& Orsini, J. (2019). Voluntary arousing negative experiences (VANE):

Why we like to be scared. Emotion, 19(4), 682. https://doi.apa.org/doi/10.1037/emo0000470

Kidd, C., \& Hayden, B. Y. (2015). The psychology and neuroscience of curiosity. Neuron, 88(3), 449-460. https://doi.org/10.1016/j.neuron.2015.09.010

King, S. (1981). Stephen King's Danse macabre. New York: Everest House.

Kirkpatrick, L. A., \& Navarrete, C. D. (2006). Reports of my death anxiety have been greatly exaggerated: A critique of terror management theory from an evolutionary perspective. Psychological Inquiry, 17(4), 288-298. https://doi.org/10.1080/10478400701366969

Koster, E. H. W., Crombez, G., Van Damme, S., Verschuere, B., \& De Houwer, J. (2004). Does imminent threat capture and hold attention? Emotion , 4(3), 312-317. https://psycnet.apa.org/doi/10.1037/1528-3542.4.3.312

Lilienfeld, S. O., \& Hess, T. H. (2001). Psychopathic personality traits and somatization: Sex differences and the mediating role of negative emotionality. Journal of Psychopathology and Behavioral Assessment, 23(1), 11-24. https://doi.org/10.1023/A:1011035306061

Lilienfeld, S. O., Widows, M. R., \& Staff, P. A. R. (2005). Psychopathic personality inventory $^{\mathrm{TM}}$-revised. Social Influence (SOI), 61(65), 97.

Loewenstein, G. (1994). The psychology of curiosity: A review and reinterpretation. Psychological Bulletin, Vol. 116, pp. 75-98. https://doi.apa.org/doi/10.1037/00332909.116.1.75 


\section{PSYCHOLOGY OF MORBID CURIOSITY}

Mack, D. (2020, March). Everyone is Watching “Contagion,” A 9-Year-Old Movie About a Flu Outbreak. BuzzFeed News. https://www.buzzfeednews.com/article/davidmack/contagionmovie-coronavirus.

Mar, R. A., \& Oatley, K. (2008). The function of fiction is the abstraction and simulation of social experience. Perspectives on psychological science, 3(3), 173-192. https://doi.org/10.1111\%2Fj.1745-6924.2008.00073.x

Martin, G. N. (2019). (Why) do you like scary movies? A review of the empirical research on psychological responses to horror films. Frontiers in psychology, 10, 2298. https://doi.org/10.3389/fpsyg.2019.02298

Morin, O., Acerbi, A., \& Sobchuk, O. (2019). Why people die in novels: testing the ordeal simulation hypothesis. Palgrave Communications, 5(1), 1-10. https://doi.org/10.1057/s41599-019-0267-0.

Navarrete, C. D., \& Fessler, D. M. (2005). Normative bias and adaptive challenges: A relational approach to coalitional psychology and a critique of terror management theory. Evolutionary Psychology, 3(1), 147470490500300121. https://doi.org/10.1177\%2F147470490500300121

Niehoff, E., \& Oosterwijk, S. (2020). To know, to feel, to share? Exploring the motives that drive curiosity for negative content. Current Opinion in Behavioral Sciences, 35, 56-61. https://doi.org/10.1016/j.cobeha.2020.07.012

Nunnally, J. C. (1978). Psychometric theory (2nd ed.). McGraw-Hill.

Olatunji, B. O., Williams, N. L., Tolin, D. F., Abramowitz, J. S., Sawchuk, C. N., Lohr, J. M., \& Elwood, L. S. (2007). The Disgust Scale: item analysis, factor structure, and suggestions for refinement. Psychological assessment, 19(3), 281. https://doi.org/10.1037/1040- 


\section{PSYCHOLOGY OF MORBID CURIOSITY}

\section{$\underline{3590.19 .3 .281}$}

Oosterwijk, S. (2017). Choosing the negative: A behavioral demonstration of morbid curiosity. PloS One, 12(7), e0178399. https://doi.org/10.1371/journal.pone.0178399

Oosterwijk, S., Snoek, L., Tekoppele, J., Engelbert, L. H., \& Scholte, H. S. (2020). Choosing to view morbid information involves reward circuitry. Scientific reports, 10(1), 1-13. https://doi.org/10.1038/s41598-020-71662-y

Pascalis, O., \& Kelly, D. J. (2009). The Origins of Face Processing in Humans: Phylogeny and Ontogeny. Perspectives on Psychological Science, Vol. 4, pp. 200-209. https://doi.org/10.1111\%2Fj.1745-6924.2009.01119.x

Revelle, W. (2018) psych: Procedures for Personality and Psychological Research. (R package version $=1.8 .12$.) Evanston, IL: Northwestern University, https://CRAN.Rproject.org/package $=$ psych .

Robinson, T., Callahan, C., \& Evans, K. (2014). Why do we keep going back? AQ method analysis of our attraction to horror movies. Operant Subjectivity, 37(1/2), 41-57. https://doi.org/10.15133/j.os.2014.004

Rosseel, Y. (2012). Lavaan: An R package for structural equation modeling and more. Version 0.5-12 (BETA). Journal of statistical software, 48(2), 1-36. http://dx.doi.org/10.18637/jss.v048.i02.

Rozin, P., Haidt, J., \& McCauley, C. R. (2008). Disgust. In M. Lewis, J. M. Haviland-Jones, \& L. F. Barrett (Eds.), Handbook of emotions (p. 757-776). The Guilford Press.

Scalise Sugiyama, M. (2006). "Lions and Tigers and Bears: Predators as a Folklore Universal." In Anthropology and Social History: Heuristics in the Study of Literature, ed. H. Friedrich, F. Jannidis, U. Klein, K. Mellmann, S. Metzger, and M. Willems, 319-331. Paderborn: 


\section{PSYCHOLOGY OF MORBID CURIOSITY}

Mentis.

Scalise Sugiyama, M. (2021). The fiction that fiction is fiction. ASEBL Journal, 15, 8-11.

Schechter, H. (2005). Savage Pastimes: A Cultural History of Violent Entertainment. Macmillan.

Scrivner, C. (2021). An infectious curiosity: Morbid curiosity and media preferences during a pandemic. Evolutionary Studies in Imaginative Culture, 5(1).

Scrivner, C., Choe, K. W., Henry, J., Lyu, M., Maestripieri, D., \& Berman, M. G. (2019).

Violence reduces attention to faces and draws attention to points of contact. Scientific reports, 9. https://dx.doi.org/10.1038\%2Fs41598-019-54327-3

Scrivner, C., \& Christensen, K. A. (2021). Scaring away anxiety: Therapeutic avenues for horror fiction to enhance treatment for anxiety symptoms. PsyArXiv. https://doi.org/10.31234/osf.io/7uh6f

Scrivner, C., Holbrook, C., Fessler, D. M., \& Maestripieri, D. (2020). Gruesomeness conveys formidability: Perpetrators of gratuitously grisly acts are conceptualized as larger, stronger, and more likely to win. Aggressive Behavior, 46(5), 400-411. https://doi.org/10.1002/ab.21907

Scrivner, C., Johnson, J. A., Kjeldgaard-Christiansen, J., \& Clasen, M. (2021). Pandemic practice: Horror fans and morbidly curious individuals are more psychologically resilient during the COVID-19 pandemic. Personality and individual differences, 168, 110397. https://doi.org/10.1016/j.paid.2020.110397

Shaw, R. L. (2004). Making sense of violence: A study of narrative meaning. Qualitative Research in Psychology, 1(2), 131-151. https://doi.org/10.1191/1478088704qp009oa

Solomon, S., Greenberg, J., \& Pyszczynski, T. (2015). The worm at the core: On the role of death in life. Random House. 


\section{PSYCHOLOGY OF MORBID CURIOSITY}

Stone, P., \& Sharpley, R. (2008). Consuming dark tourism: A thanatological perspective. Annals of tourism Research, 35(2), 574-595. https://doi.org/10.1016/j.annals.2008.02.003

Turner, S. A., Jr, \& Silvia, P. J. (2006). Must interesting things be pleasant? A test of competing appraisal structures. Emotion , 6(4), 670-674. https://psycnet.apa.org/doi/10.1037/1528$\underline{3542.6 .4 .670}$

Vicary, A. M., \& Fraley, R. C. (2010). Captured by true crime: Why are women drawn to tales of rape, murder, and serial killers?. Social Psychological and Personality Science, 1(1), 81-86. https://doi.org/10.1177\%2F1948550609355486

von Borries, A. K. L., Volman, I., de Bruijn, E. R. A., Bulten, B. H., Verkes, R. J., \& Roelofs, K. (2012). Psychopaths lack the automatic avoidance of social threat: relation to instrumental aggression. Psychiatry Research, 200(2-3), 761-766.

https://doi.org/10.1016/j.psychres.2012.06.026

Wabnegger, A., Höfler, C., Zussner, T., Freudenthaler, H. H., \& Schienle, A. (2021). Enjoyment of watching pimple popping videos: an fMRI investigation. Behavioural Brain Research, 113129. https://doi.org/10.1016/j.bbr.2021.113129

Wheaton, M. G., Holman, A., Rabinak, C. A., Macnamara, A., Proudfit, G. H., \& Phan, K. L. (2013). Danger and disease: electrocortical responses to threat- and disgust-eliciting images. International Journal of Psychophysiology: Official Journal of the International Organization of Psychophysiology, 90(2), 235-239. https://doi.org/10.1016/j.ijpsycho.2013.08.001

Xu, M., Li, Z., Ding, C., Zhang, J., Fan, L., Diao, L., \& Yang, D. (2015). The Divergent Effects of Fear and Disgust on Inhibitory Control: An ERP Study. PloS One, 10(6), e0128932. https://doi.org/10.1371/journal.pone.0128932 


\section{PSYCHOLOGY OF MORBID CURIOSITY}

Zuckerman, M., \& Litle, P. (1986). Personality and curiosity about morbid and sexual events.

Personality and Individual Differences, Vol. 7, pp. 49-56. https://doi.org/10.1016/0191$\underline{8869(86) 90107-8}$ 


\section{The Psychology of Morbid Curiosity: Development and Initial Validation of the Morbid Curiosity Scale}

\section{Supplementary Materials}

\section{Study 1a Method and Participants}

An initial pool of 24 items was generated. Eleven items from the Curiosity About Morbid Events scale (Zuckerman \& Litle, 1986) were included in the pool and other items were constructed based on the hypothesis that morbid curiosity would encompass an interest in events that feature violence and horror. Participants from Amazon Mechanical Turk (MTurk; $n=206$ ) rated their agreement or disagreement with each item from 1 (strongly disagree) to 7 (strongly agree). After removing ten participants who did not answer every question and four outliers identified using Mahalanobis distance $\left(X^{2}(24)=51.18\right), 192$ participants remained in the exploratory factor analysis sample.

\section{Study 1a Results}

The pool of items for the first iteration of the scale can be found in Supplementary Table 1. A scree plot and parallel analysis suggested two factors. After removing items with communalities less than 0.20 , items that did not load, and items that loaded onto more than one factor in a stepwise fashion, a three-factor model consisting of 15 items emerged. However, two of the factors only had two items and the third factor did not have a clear topical trend. Roughly, 


\section{PSYCHOLOGY OF MORBID CURIOSITY}

the two smaller factors were about the human body and horror movies, while the larger one was a mix of items relating to violence, death, and gore.

\section{Study 1 b Method and Participants}

To further investigate the factor structure, the pool of items was modified. Eleven items were kept and/or slightly modified from the first iteration of the scale and 13 new items were added. Based on exploratory factor analysis of the first iteration of the scale, five broad categories were investigated in the second iteration: dangerous people, death, violence, supernatural, and the body. New participants from MTurk $(\mathrm{n}=206)$ rated their agreement or disagreement with each item from 1 (strongly disagree) to 7 (strongly agree).

\section{Study $1 b$ Results}

The pool of items for the second iteration of the scale can be found in Supplementary Table 2. After removing four participants who did not answer every question and two outliers identified using Mahalanobis distance $\left(X^{2}(24)=51.18\right), 200$ participants remained in the exploratory factor analysis sample. A scree plot and parallel analysis suggested two factors. After removing items with communalities less than 0.20 and items that loaded onto more than one factor in a stepwise fashion, a three-factor model consisting of 17 items emerged. One factor consisted of four body-related items, one contained supernatural and dangerous people items, and the third contained death, supernatural, and body items. Based on this factor analysis, body, supernatural, dangerous people, and death seemed to be the salient factors. 
PSYCHOLOGY OF MORBID CURIOSITY

\section{Study 1c Method and Participants}

Seventeen items from the previous iteration were included alongside 19 new items. The 36 items fell broadly into four categories: violations of the body, death of a person, minds of dangerous people, and supernatural. New participants from MTurk $(\mathrm{n}=243)$ rated their agreement or disagreement with each item from 1 (strongly disagree) to 6 (strongly agree). A 6point scale was used in order to remove the neutral option. Given the extreme nature of the questions, it is unlikely that many participants truly feel neutral, and some may select neutral as a way to not answer a question about a situation that could be considered morally questionable (e.g., attending an execution). After removing two participants who did not answer every question and six outliers identified using Mahalanobis distance $\left(X^{2}(36)=67.99\right), 235$ participants remained in the exploratory factor analysis sample.

\section{Study 1c Results}

The pool of items for the third iteration of the scale can be found in Supplementary Table 3. A scree plot and parallel analysis suggested four factors. After removing items with communalities less than 0.20 , items that did not load onto a factor, and items that loaded onto more than one factor in a stepwise fashion, a three-factor model consisting of 24 items emerged. Items relating to the minds of dangerous people loaded onto a single factor as did supernatural items. The third factor was a mix of body violations and death. One thing that appeared to be distinct in the items from factor three was whether or not the item was about the body itself or a violent act. Moreover, each of the items appeared to be about a type of threat - either to the body, from another person, or from a supernatural source. More specifically, the items appeared to reflect an interest in learning about these threats either through witnessing them, reading about 
PSYCHOLOGY OF MORBID CURIOSITY

them, or otherwise learning about them, but not necessarily by engaging with them more intimately (e.g., performing the action personally). In light of this, a fourth version of the scale was created.

\section{Supplementary Tables}

\section{Supplemental Table 1}

Study la items

1 I think it could be interesting to tour a house where a serial killer murdered his victims

2 I think horror movies are usually entertaining

3 I would be curious to see how an autopsy is performed

4 I would be interested in seeing a new horror movie

5 If I could travel back in time to Ancient Rome, I would be curious enough to attend a gladiatorial fight.

6 I would be interested in visiting a place where many people died in a tragic event

7 I would be curious to see what some toxic substances do to the body

8 I would never want to investigate a supposedly haunted place

9 I am curious about crime and enjoy reading detailed news accounts about murders and other violent crimes

10 I would be interested in visiting a museum that contained shrunken heads and skeletons

11 Although I don't want people to get hurt, violent accidents are sometimes interesting to see

12 I would not be able to look at a serious injury like a gunshot wound

13 If given the opportunity, I would attend the execution of a criminal

14 I would be interested in interviewing a serial killer

15 News reports about violence, no matter how gory, are sometimes necessary so that people do not have any illusions about these topics

16 I would not be interested in watching a documentary about a mass suicide in a cult

17 I would never want to look at a dead person

18 I would find it interesting to watch a major surgical operation being performed

19 I prefer the violence in films and television shows to be uncensored, even if it is gory

20 Under no circumstances would I be interested in seeing a video of a person being killed

21 If I came across a gruesome video online, I would be curious enough to click on it

22 I would never be interested in participating in a supposedly supernatural event such as a séance or playing with a Ouija board 
PSYCHOLOGY OF MORBID CURIOSITY

23 When I see a serious car accident on the road I typically slow down to see what has happened

24 I often find scary or creepy things interesting

\section{Supplemental Table 2}

Study $1 \mathrm{~b}$ items

1 I would not be interested in touring a house where a serial killer murdered his victims.

2 I think the supernatural is an interesting topic.

3 I would be curious to see how an autopsy is performed

4 I would be interested in seeing a new horror movie

5 If a famous killer published a book about his life, I would be interested in reading it.

$6 \quad$ I would not want to own a human skull under any circumstances

7 Under no circumstances would I be interested in seeing a video of a person being killed

8 I would be interested in learning about shrunken heads

9 I am curious about crime and enjoy reading detailed news accounts about murders and other violent crimes

10 I would be interested in seeing how limb amputation works

11 I would never be interested in visiting a place that is supposed to be haunted

12 I would not want to look at a serious injury like a gunshot wound

13 I would never be interested in visiting a place where many people were murdered

14 I would be interested in interviewing a serial killer

15 If there was a fatal car wreck on the side of the road and the police were already present, I would try to catch a glimpse of the body

16 I find the Occult interesting

17 I am curious about the different ways people can die

18 I would never want to watch a major surgical operation being performed

19 I would be interested in attending an exorcism

20 I would be curious to see what some toxic substances do to the body

21 If I came across a video of a gruesome murder online, I would be curious enough to click on it

22 I am not interested in seeing what kind of damage a grenade would do to the human body

23 If I lived in Medieval Europe, I would be interested in attending a public execution

24 I find crime shows interesting 


\section{Supplemental Table 3}

Study 1c items

1 I am not interested in seeing what kind of damage a grenade would do to the human body.

2 If a head transplant was possible, I would want to watch the procedure.

3 If a famous killer published a book about his life, I would be interested in reading it.

$4 \quad$ I think the supernatural is an interesting topic.

5 Under no circumstances would I be interested in seeing a video of a person being killed.

6 I would be curious to see how an autopsy is performed.

7 I find crime shows boring.

8 I would be interested in attending or watching a video of an exorcism.

9 If I came across a video of a gruesome murder online, I would be curious enough to click on it.

10 I would be curious to see what some toxic substances do to the body.

11 I am curious about crime and enjoy reading detailed news accounts about murders and other violent crimes.

12 I find the Occult interesting.

13 If there was a fatal car wreck on the road and the police were already present, I would try to catch a glimpse of the body.

14 I would never want to watch a major surgical operation being performed.

15 I would be interested in watching a documentary on motives behind real murders.

16 Under no circumstances would I be interested in visiting a place that is supposed to be haunted.

17 If I lived in Medieval Europe, I would be interested in attending a public execution.

18 I am interested in seeing how limb amputation works.

19 My favorite part of a crime show is learning about why the killer did what he did.

20 I would be interested in visiting a museum of shrunken heads.

21 I am not easily disgusted by gore.

22 I think extreme or painful rituals are interesting to learn about.

23 If I had to be part of a jury, I would want the suspect on trial to be a serial killer.

24 A documentary on Voodoo would interest me.

25 I am curious about the ways that people can die.

26 I would like to see how bodies are prepared for funerals

27 I am intrigued by villains and evil characters in stories. 
28 If I found an ancient book on demons, I would want to look inside.

29 If I lived in Ancient Rome, I would be interested in attending a gladiatorial fight.

30 I think the preservation of bodies, like those used in taxidermy, is interesting.

31 If I was given the choice to play a good character or an evil character in a game, I would play the evil character.

32 Dark magic is more interesting to me than other kinds of magic.

33 I do not find the human body very interesting.

34 Being a homicide detective would not be very interesting.

35 If I had to choose a character for a video game, I would pick a melee over spell-caster.

36 If I saw a street fight break out, and knew I could not intervene, I would try to watch it.

\section{Supplemental Table 4}

Items removed from the 29-item pool in Study 1d

1 Under no circumstances would I be interested in seeing a video of a person being murdered.

2 If a famous killer published a book about his life, I would be interested in reading it.

3 I would never want to watch a major surgical operation being performed.

4 Under no circumstances would I be interested in visiting a place that is supposed to be haunted.

5 Ghosts and/or spirits are probably real.

\section{Supplementary Table 5}

Regression model for Morbid Curiosity and Big Five Personality (TIPI)

\begin{tabular}{lcccc} 
Genre & $\boldsymbol{\beta}$ & $\boldsymbol{S} \boldsymbol{E}$ & $\boldsymbol{t}$ & $\boldsymbol{p}$ \\
\hline Emotionality & -0.04 & 0.04 & -1.05 & .295 \\
Conscientiousness & -0.07 & 0.04 & 1.69 & .093 \\
Agreeableness & -0.13 & 0.04 & -2.85 & .005 \\
Extraversion & 0.02 & 0.03 & 0.51 & .608 \\
Openness & 0.03 & 0.05 & 0.67 & .501
\end{tabular}




\section{Supplementary Figures}

\section{Parallel Analysis Scree Plots}

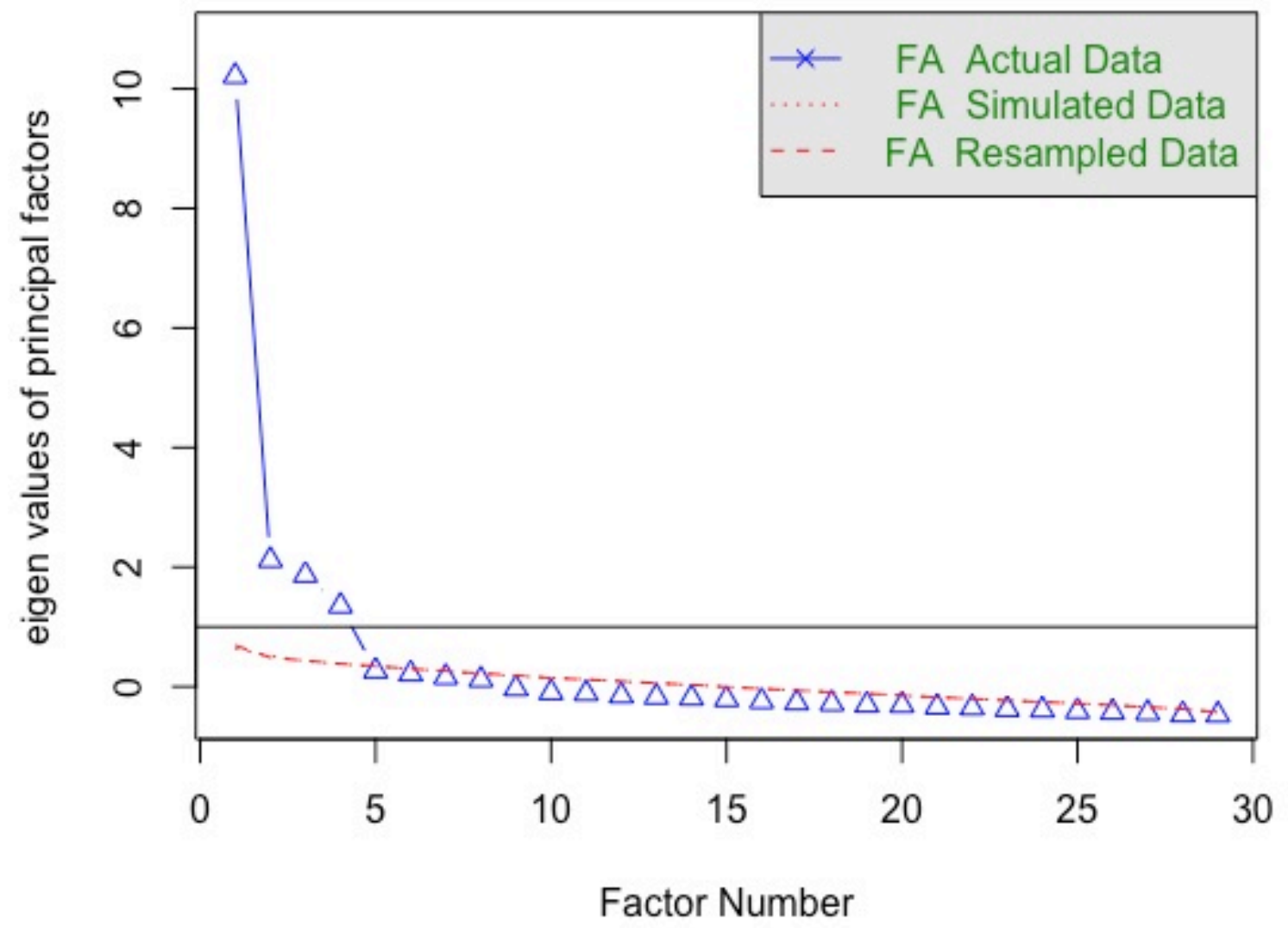

Supplementary Figure 1. Scree plot indicating a four-factor structure of the Morbid Curiosity Scale from Study 1. 
PSYCHOLOGY OF MORBID CURIOSITY

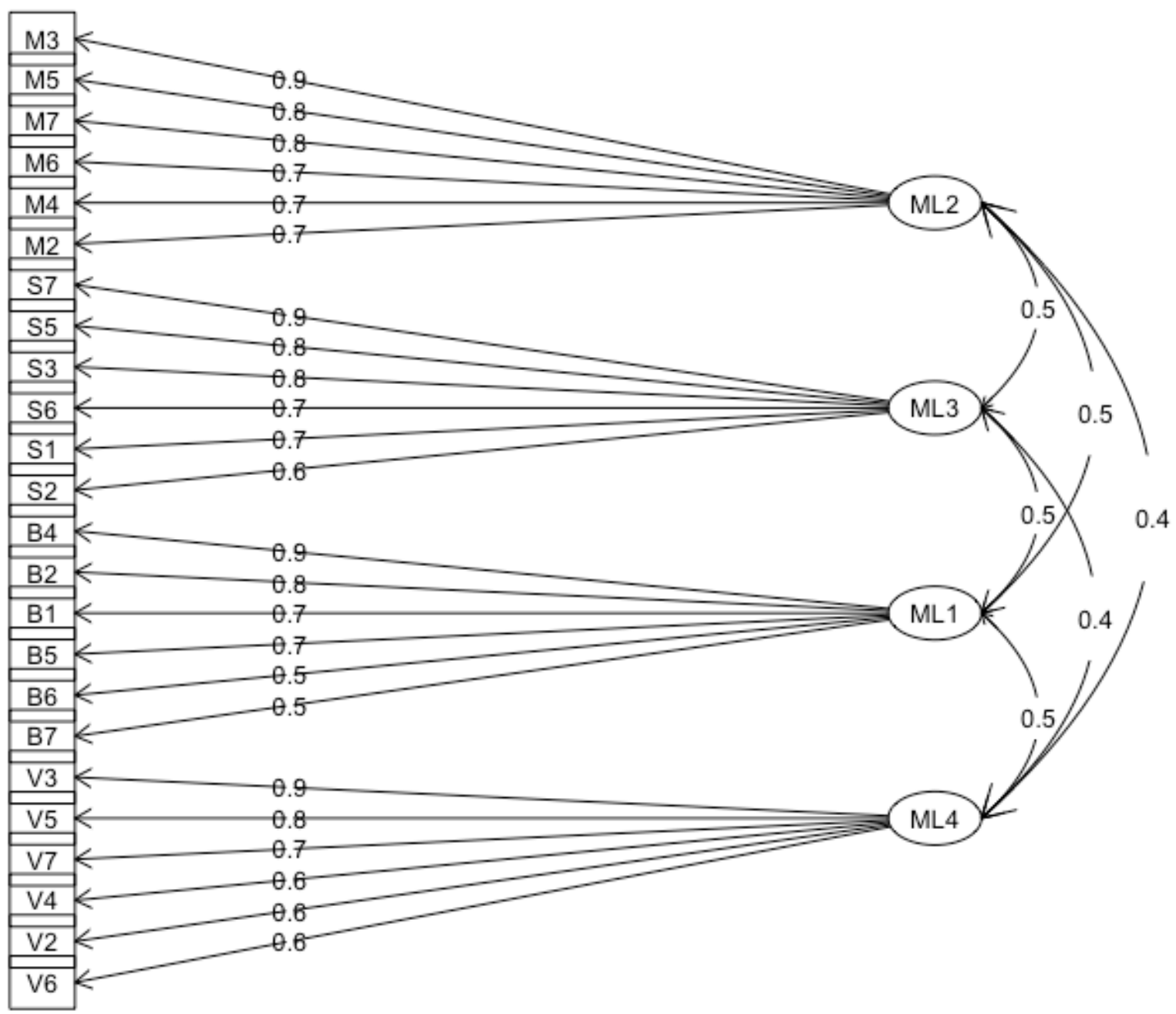

Supplementary Figure 2. Factor structure of the 24-item Morbid Curiosity Scale. 


\section{Morbid Curiosity Histogram - Study 3}

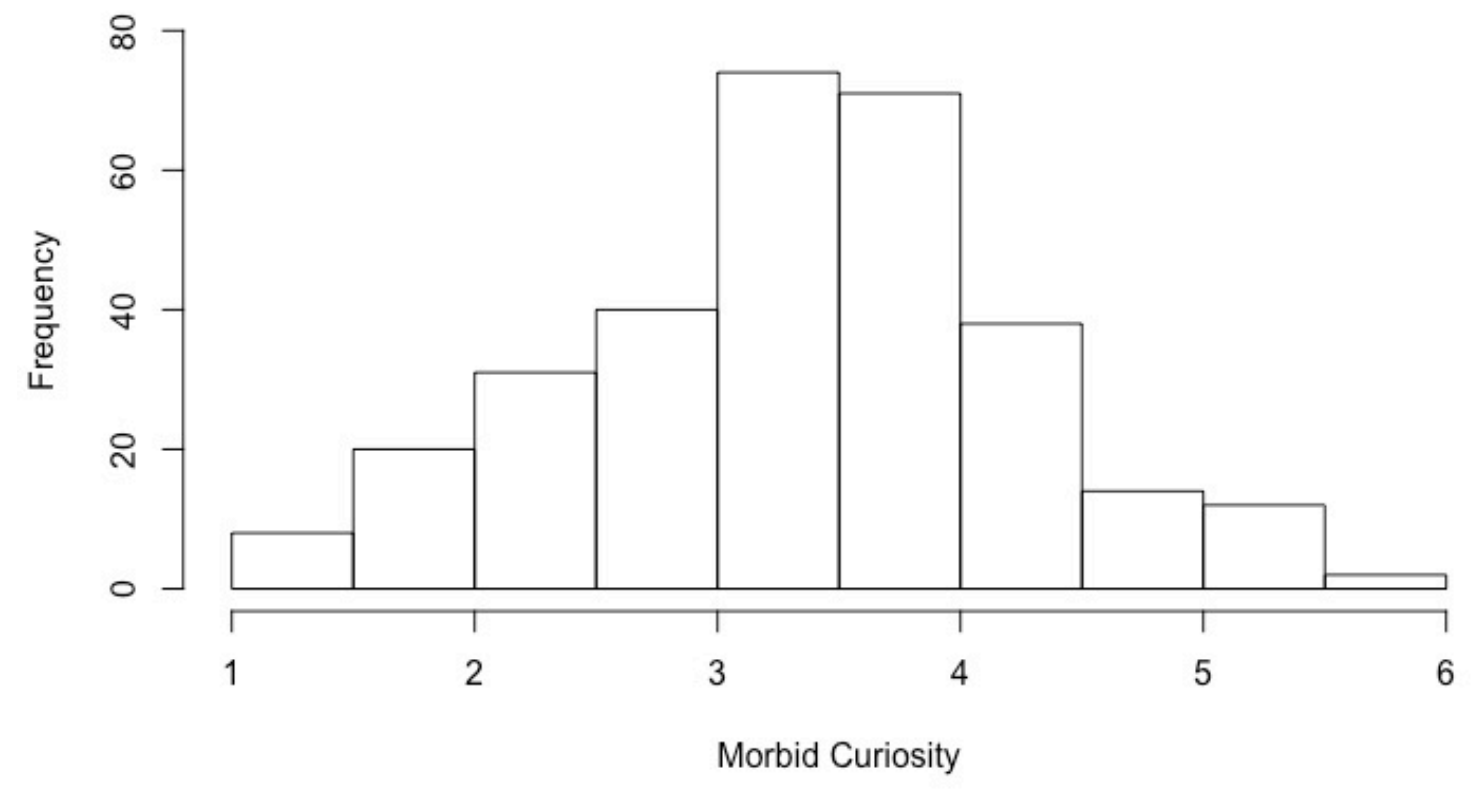

Supplementary Figure 3. Histogram of scores on the Morbid Curiosity Scale in Study 3.

\section{Morbid Curiosity Histogram - Study 3 retest}

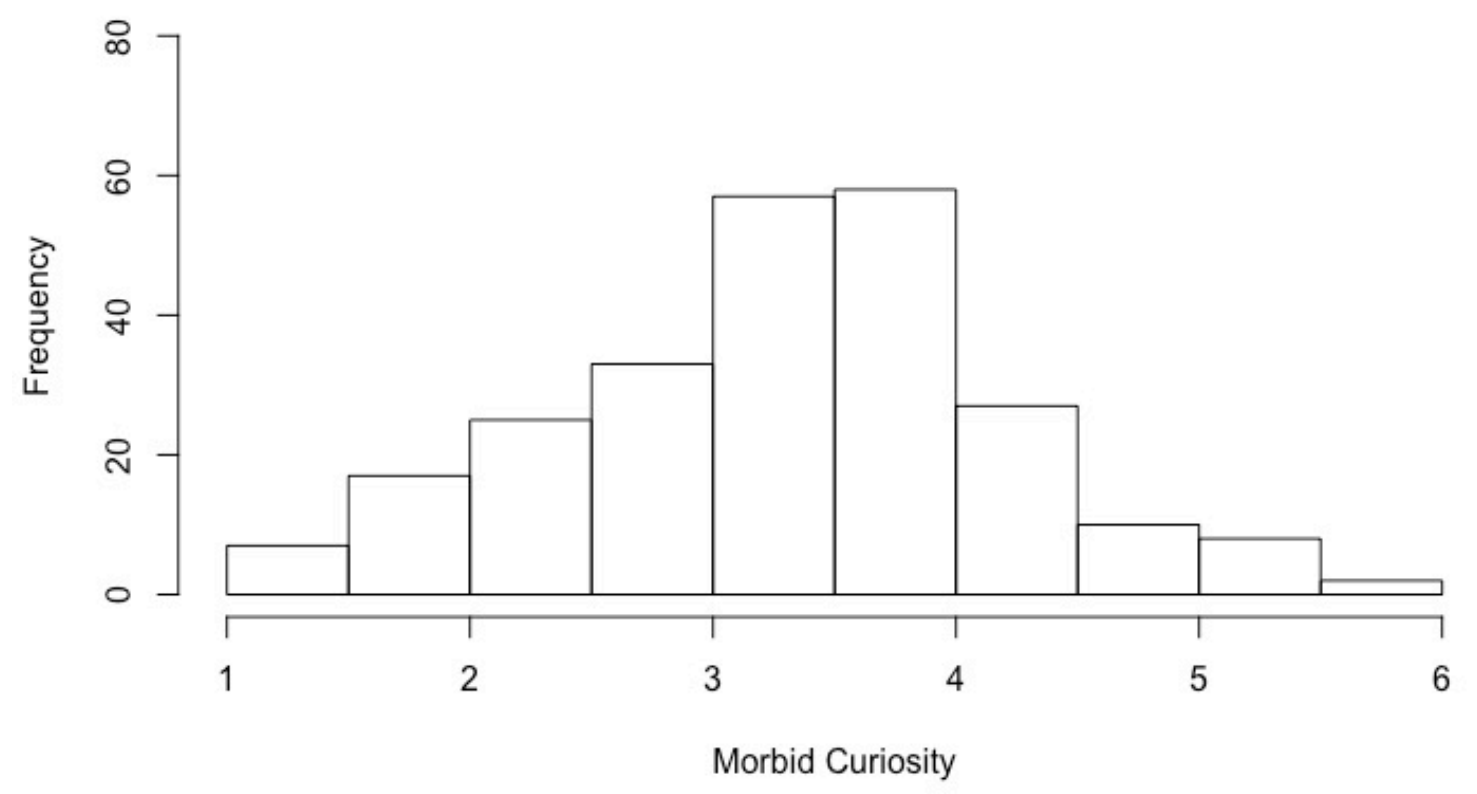

Supplementary Figure 4. Histogram of scores on the Morbid Curiosity Scale retest in Study 3. 